\title{
Acorea- An Isolated Presenting Feature
}

\section{Aeshvarya D, Manisha G and Smita K*}

Department Of Ophthalmology, Shri Mahant Indiresh Hospital, India

\section{Case Report}

Volume 3 Issue 5

Corresponding author: Smita Kapoor, Department Of Ophthalmology, Shri Mahant

Indiresh Hospital, Dehradun, India, Email: smitakapoor21@yahoo.in

\section{Abstract}

Stimulus deprivation amblyopia occurs when there is obstruction to light entering the eye and that leads to an unclear image being formed on the retina. The most common causes are congenital cataract, corneal opacity and ptosis. Acorea, though a rare cause can lead to dense amblyopia. This case report explains the need for early diagnosis and intervention in such cases.

Keywords: Amblyopia; Ptosis; Corneal Opacity; Dysgenesis; Gonoiscopy

\section{Introduction}

Acorea is the absence of pupillary aperture. It can be associated with microphthalmos, cataract, and iridocorneal dysgenesis which is suspected to result from an autosomal dominant mutation. Early diagnosis and treatment can help prevent the development of stimulus deprivation amblyopia. Here we report a case of acorea with no associated anterior segment findings.

\section{Case Report}

A10 year old male presented with complaints of defective vision and outward deviation of the right eye since the age of 4 years. There was no history of any previous treatment. Gestational history was negative and the other siblings were normal. There was no history of trauma and no systemic abnormalities were found on paediatric evaluation.

On examination right eye showed a divergent squint of
50 prism dioptres. Best corrected visual acuity in the right eye was hand movements and projection of rays were accurate in all quadrants, left eye was 6/6 and N6. On slit lamp examination cornea was clear, anterior chamber was of normal depth, iris pattern was lost and the pupillary aperature was absent suggestive of acorea in the right eye (Figure 1). Intraocular pressure in the right eye was $14 \mathrm{mmHg}$. Gonoiscopy revealed normal angle structures with no dysgenesis. Bscan was normal. Left eye showed no abnormality. 1\% atropine eye ointment was instilled twice a day in the right eye for 3 days. A slit like opening was obtained on the $3^{\text {rd }}$ follow up day (Figure 2). Right eye pupilloplasty was planned under general anaesthesia. The opening obtained after atropinisation was used as an initiation point and with the help of vitrectomy cutter a $4 \mathrm{~mm}$ pupillary aperture was created (Figure 3). On follow up, the child started fixing with the right eye and the vision improved to finger counting at 1 meter. Fundus examination revealed no abnormality (Figure 4). Spectacle correction was given and anti amplyopia treatment was started. 

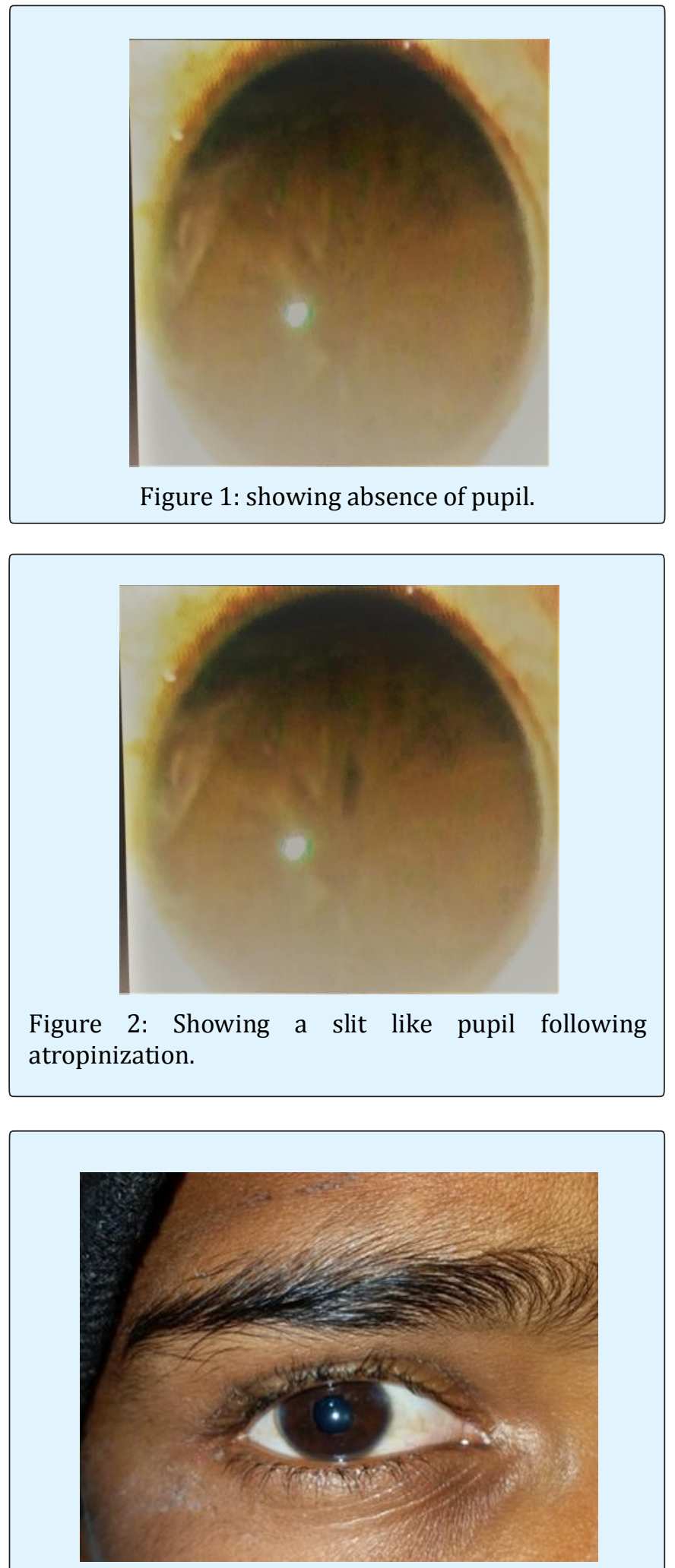

Figure 3: Showing 4mm pupil following pupilloplasty.

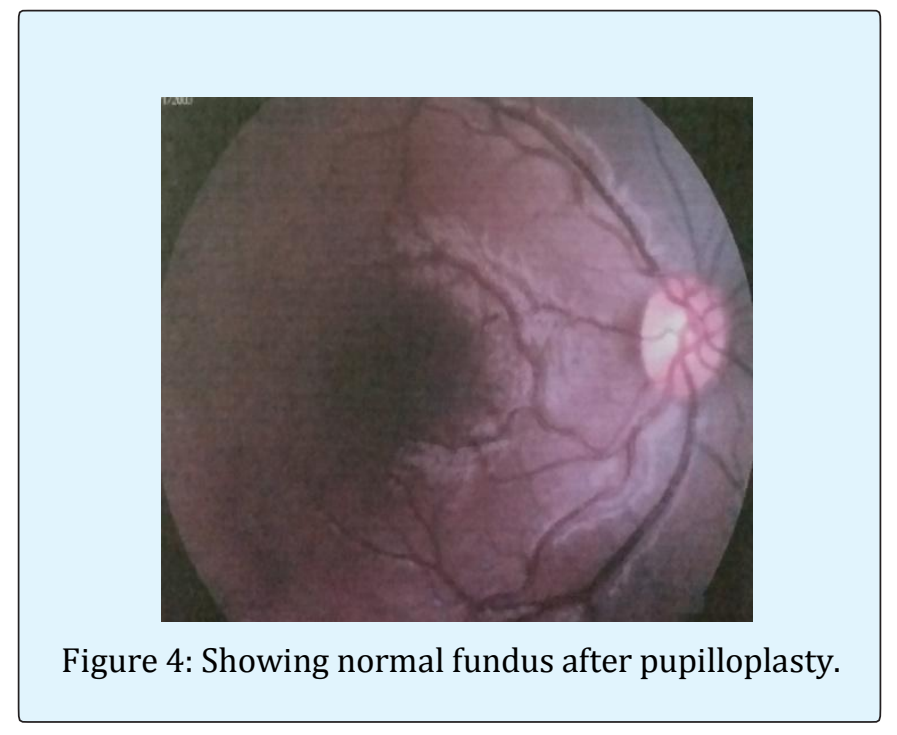

\section{Discussion}

The pupil is formed during embryogenesis as a stromal layer with the anterior layer derived from mesodermal a tissue which regresses at the $60-\mathrm{mm}$ embryonic stage. To control the quantity of light that enters the eye, the pupil constantly changes its size by the reciprocal actions of the dilator and sphincter muscles. Both types of muscles are derived from the epithelial layer, that is, the posterior layer of the iris that is opposed to the crystalline lens. Congenital anomalies of the pupil are quite varied, ranging from minor to major abnormalities that prevent the full development of vision. Common abnormailities of the pupil include polycoria (more than one pupil), dyscoria (abnormal shape of the pupil) and corectopia (abnormal position of the pupil). Apart from the above, normal round pupils with sphincter pupillae can also demonstrate anomalies. Congenital microcoria are defined as a pupil of $\leq 2.0 \mathrm{~mm}$ diameter which is caused byaberrant development of the dilator muscle of the iris. It is also associated with impairment in pupillary activity that can result in reduced visual function. Persistent pupillary membrane results from failure of regression of the mesodermal vasculature. This condition rarely affects vision unless the membrane obstructs the pupil.

A more severe anomaly of the pupil is acorea where the pupil is completely absent. Acorea is similar to both microcoria and persistent pupillary membrane, but can affect vision more severely than either of the two conditions. Acorea appears to be inherited in an autosomal dominant fashion. 5 cases of an affected family 


\section{Open Access Journal of Ophthalmology}

presenting with acorea, microphthalmos and cataract have been reported [1]. Genetic linkage studies have shown location of possible genes to be chromosomes 1,5 , 8,11 and 17. In contrast to the above case report our patient had an isolated finding of acorea without any other feature of anterior segment dysgenesis or cataract associated with it. Literature search revealed only onne such report [2]. lsolated cases of acorea can be dealt with a simple surgical approach of pupilloplasty and early intervention in such cases can decrease the chances of stimulus deprived amblyopia and sensory strabismus.

\section{References}

1. Kondo H, Tahira T, Yamamoto K, Tawara A (2013) Familial acorea, microphthalmia and cataract syndrome. Br J Ophthalmol 97(9): 1155-1160.

2. Ramasubramanian S, Majumder PD (2018) Acorea: A rare congenital anomaly. Indian Journal of Ophthalmology 66(3): 450.

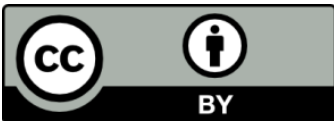

